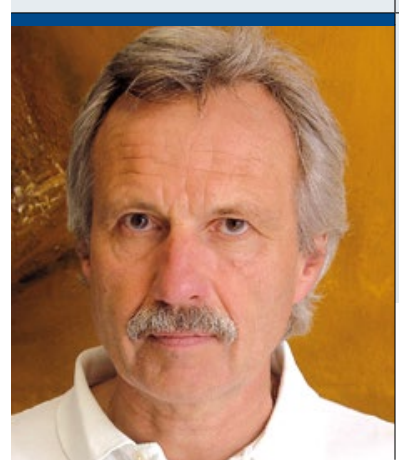

"Wenn es um die Pfründe geht, ist Schluss mit lustig."

\title{
GOÄ-Novelle: Geld oder Ärger
}

$\mathrm{E}$

rst warf der Verhandlungsführer das Handtuch, dann folgte das Aus für die Novelle der Gebührenordnung für Ärzte (GOÄ). Während "Monty“ das Projekt als nicht vollständig gescheitert ansah, waren die Verbandsfürsten wohl anderer Ansicht. Der NAV-Virchow-Bund sprach von einer „insgesamt verunglückten GOÄ-Novelle“, der Berufsverband Deutscher Internisten (BDI) bezeichnete die Verhandlungsführung als „dilettantisch schlecht" und stellte fest, dass man nun vor einem "Scherbenhaufen" stehe und der Spitzenverband Fachärzte Deutschland (SpiFa) kommentierte, dass Montgomery mit seiner "Chefsache GÖ̈“ auf ganzer Linie gescheitert sei und der vorgelegte „Entwurf den Interessen der Ärzteschaft nicht nutzt, sondern schadet". Sollte wohl heißen dem Portemonnaie schadet oder wie es der SpiFa so karitativ formulierte: „Das Festlegen ausgewogener Preise schützt die Patienten vor finanzieller Überforderung und vergütet angemessen die ärztlichen Leistungen. Nicht unterschreitbare Gebührensätze gewährleisteten eine menschlich und qualitativ hochwertige Patientenversorgung."

Wenn es um die Pfründe geht, ist Schluss mit lustig. Der PKV-Verband kommentierte trocken, es bestehe seitens der BÄK das Leistungsverzeichnis betreffend „weiterer Diskussionsbedarf" und das Bundesgesundheitsministerium (BMG) schweigt und ist, wie man hört, „not amused“. Noch vor kurzem hatte Gröhe Dampf gemacht, die Novelle an den Start zu bringen; wurde doch der Kabinettsentwurf in der Gesetzesvorhabenplanung des BMG für Sommer 2016 angekündigt.

\section{Konsentierter Dissens}

Nur Montgomery schien weiterhin guter Dinge. Er meinte, dass nun "normale Tarifverhandlungen“ anstünden (die Vorstellungen von 370.000 berufstätigen Ärzten schwanken zwischen zweistelligem Honorarplus und einem frei flottierenden Inflationsausgleich über Steigerungssätze) und wertete den Forderungskatalog der Allianz deutscher Ärz- teverbände als konstruktive Kooperation. Gemeint ist wohl kooperierende Destruktion. Die zwölf Punkte des Forderungspakets der Allianz stellen die gesamte Novelle in Frage. Gefordert wird, nicht nur den Bewertungs- und Legendenteil neu zu verhandeln, sondern auch die Änderungen des Paragrafenteils und der Bundesärzteordnung. Bei den Neuverhandlungen erwartet der BDI ein wesentlich partnerschaftlicheres Verhalten der PKV und dass die Novelle der GOÄ keine „Einbahnstraße zur Kosteneinsparung von Versicherungsgesellschaften wird“. Man könne dies durch Einbindung der Berufsverbände in die Verhandlungen erreichen. Angesichts divergierender Verbandsinteressen, erscheint Flöhe hüten erfolgversprechender. So ruft die freie Ärzteschaft ihre Mitglieder auf, in Eigenregie den Inflationsausgleich über den Steigerungssatz herzustellen, die Hausärzte wollen ihr eigenständiges Kapitel, der Spitzenverband ZNS will seine "Standpunkte eigenverantwortlich publizieren“, da er kein Mitglied der SpiFa mehr sei.

\section{Rien ne va plus}

Damit ist eine Verabschiedung der Novelle in dieser Legislaturperiode Geschichte. Denn die neue GOÄ wird als Rechtsverordnung vom BMG mit Zustimmung des Bundesrates erlassen. Rochell hatte schon im Vorfeld gewarnt: „Es gibt kein Wunschprogramm!“ Die Bundesregierung betreibe „die Erneuerung der GÖ̈“ und „ein schmerzhafter Kompromiss zwischen PKV-Verband, Beihilfe und BÄK“ sei zu erwarten. Auf dem jüngsten Spitzentreffen der Verbandsvertreter am 12. Mai 2016 war man sich einig, die Position der Ärzteschaft müsse nicht dem Ordnungsrahmen des Bundesministeriums entsprechen. Neues Spiel, neues Glück oder Theo gegen den Rest der Welt!?

Ihr



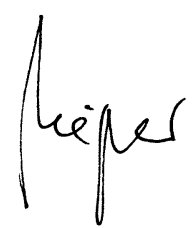

